\author{
Military Technical College \\ Kobry El-Kobbah, \\ Cairo, Egypt.
}

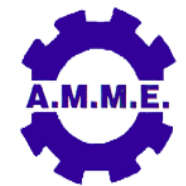

$18^{\text {th }}$ International Conference on Applied Mechanics and Mechanical Engineering.

\title{
STRUCTURAL DESIGN OPTIMIZATION OF A MEDIUM ALTITUDE LONG ENDURANCE (MALE) UAV WING
}

\author{
S. A. Almbrok ${ }^{1}$, M. M. Hegaze ${ }^{2}$, M. A. Kamel ${ }^{2}$ and M. S. Asfoor ${ }^{2}$
}

\begin{abstract}
The objective of this paper is to obtain an optimal weight of wing spar by obtaining the optimal cross-section parameters of I-section wing spars, subjected to aerodynamic and mass loads.

Using Matlab codes to apply several methods of optimization and then compare the results of those methods. After calculating the wing weight by the classical methods, optimization methods are applied to get weight minimization. Thus, the objective of the optimization methods is the wing weight. Four different optimization methods are used in this study. The first method is a graphical optimization method (with one design parameter) used as the primary method to determine the variables range and the effect of each spar on the wing weight. The second, third, and fourth optimization methods (with two design parameters) are searching method, gradient-based method, and genetic algorithm method respectively. The design parameter chosen was the flanges ratio, due to its highly participation (20 to $50 \%$ ) in the wing's total structure weight.
\end{abstract}

The optimization algorithms were utilized to analyze the effect of the cross-sectional geometrical parameters, such as width $(Z)$, height $(W)$ of the flange. The ratio between these parameters (Z/W) was one of the input data to the stress analysis process to obtain the minimal cross-section dimensions of the flange under the allowable stress of the chosen spar material. The spar is made of Aluminum 2024-T4 alloy.

The goal of the optimization is to optimize the cross section parameters of the spar to withstand the exerted load subjected to the wing, yet with the minimum spar material with the constraint of keeping that stress within the maximum yield stress of the material. The results of applying different methods are that the searching method is the best method in this case of low design variables.

\section{KEY WORDS}

Optimization weight of UAV, MALE UAV, graphical optimization method, searching method, gradient-based method and genetic algorithm method

2 Egyptian Armed Forces. 


\section{NOMENCLATURE}

MALE Medium Altitude Long Endurance.

$(z / w)_{F}$ Height-width flange ratio for front spar.

$(z / W)_{R}$ Height-width flange ratio for rear spar.

A Area.

$\mathrm{m} \quad$ Mass.

$\checkmark \quad$ Volume.

$W_{w} \quad$ Wing weight.

$\sigma_{1} \quad$ Stress on front spar.

$\sigma_{2} \quad$ Stress on rear spar.

p Density.

\section{INTRODUCTION}

The airplane weight plays an important role in the airplane structure design. The goal of the optimization is to find the ideal structure with minimum weight and maximum strength. Recently various initiatives have been pushed in order to identify and reduce costs and weight associated with material utilization in manufacturing new automotive and aerospace products. Using computer aided design with optimization algorithms helps manufacturers to come up with many competitive advantages such as minimizing the material used, lower cost, and smaller size[1, 2].

Current research efforts have sought to use computational resources to enhance and optimize part geometry based on a starting design, and improvement of the design is based on the related design variables, dependent variables and objective function[1]. Several researchers used computational resources to enhance and optimize geometries based on a starting design. An improvement of the design is based on the design variables (geometrical parameters), state variables (Constrain) and objective function (the objective function is a state variable to be minimized) [3, 4].

In this study, the procedures of wing weight calculations are introduced. In addition, wing structure dimensions optimization is performed to minimize the wing weight subjected to maximum available stress.

\section{WING WEIGHT CALCULATION}

The wing weight depends on the main dimensions of the wing internal elements, which are calculated by stress analysis [5]. The weight can be calculated by knowing the volume of each part and its corresponding density as shown in equations (1) and(2), where (i) is each part of the wing (front spar, rear spar ...etc.).

$$
\begin{gathered}
W_{i}=m_{i} g=\rho_{i} V_{i} g \\
W=\sum W_{i}
\end{gathered}
$$


According to a material survey on aluminum alloys, the aluminum 2024-T4 alloy is selected for wing main parts. The mechanical properties are given in Table 1.

The volume of each part can be calculated using a discretization method. This method discretizes each part into 100 equal elements. For each element, the volume is calculated by multiplying the mean cross-section area by the element length as shown in equation (3).

$$
V_{j+1}=V_{j}+d z\left[A_{j+1}+A_{j}\right] / 2 \quad, j=0,1,2 \ldots .100, V(0)=0
$$

After obtaining the wing parts volumes and densities, the results of the half-wing weight calculations using the ratio $z / w=5$ Fig. 1 are listed in Table 2.

\section{WING STRUCTURE OPTIMIZATION}

The optimization problem can be classified into unconstrained and constrained optimization problem. In addition, it can be classified into a linear and nonlinear optimization problem. The linear optimization problem must contain linear objective function and linear constrains. The nonlinear optimization problem must contain at least one nonlinear objective function or nonlinear constrains. There are many methods to perform optimization such as gradient-based algorithm, single and multiobjective function genetic algorithms, and hybrid optimization method.

The gradient-based algorithm uses the search routine to obtain the local optimized design parameters. The genetic algorithm has some advantages over the gradientbased algorithm where, the genetic algorithm searches from a population and not a single parameter set. In addition, it provides the global maximum/minimum not a local maximum/minimum and it operates on irregular functions (step functions). Moreover, it does not require initial estimations of the parameters and operates on a coding of the parameter set, not the parameters themselves [6].

In this study, four different methods are applied to perform the optimization. The first method is a graphical optimization method that uses one design parameter. The second, third, and fourth are searching method, gradient-based method, and genetic algorithm method respectively using two design parameters. The design parameters are chosen as the Z/W ratios, where the flanges produce $(20-50) \%$ of the wing total weight.

To perform these optimization methods, group of Matlab codes are developed. These Matlab codes consume a long time to calculate the loads, dimensions, stresses, and weights. The flow chart of these codes is shown in Fig.2, the process starts by specifying the wing main dimensions and the selected airfoil. The main code call the Sherink method function to calculate lift coefficient distribution in 100 sections span wise. Then the wing load function uses the lift coefficient distribution that results from the Schrenk's method to calculate the shear load, bending moment, and torque moment distribution. To apply the stress calculations, the wing section dimensions and areas must be obtained. Therefore, an airfoil calculation function is developed to obtain the three sections areas and arc length for each segment using 1000 section chord wise at each span wise section. By knowing all the required data, the main code calculates the binding rigidity center and shear center at each spanwise 
section. In addition, calculates stresses, flanges dimensions, and web thickness for both rear and front spares at each spanwise section. Moreover, calculates the weights of the spars, the ribs, and the wing. This loop is repeated till reaching the global minimum of the weight by changing the flanges ratios.

\section{Graphical Method}

The objective function is minimizing the wing weight subjected to structure failure and the design parameter is the height-width flange ratio $z / w$. The structure failure is represented in way that the maximum normal stresses are less than the material yield strength. The maximum normal stresses are calculated for the two spars along $z$ direction. The mathematical representation of the optimization problem can be written as follows:

Subjected to

$$
\min f(x)=W_{w}
$$

$$
\begin{aligned}
& \left(\sigma_{1}\right)_{\max } \leq\left(\sigma_{y i a l i}\right)_{\text {material }} \\
& \left(\sigma_{2}\right)_{\text {max }} \leq\left(\sigma_{y i e i d}\right)_{\text {material }} \\
& 0.5 \leq x \leq 8, \quad x=z / w
\end{aligned}
$$

The variation of wing weight and normal stresses with flange ratio are represented in Fig.3. The optimum point is selected as the ratio $z / w=1$ that located in the safe margin, where the half-wing weight is $23.5 \mathrm{Kg}$. Fig.4.show the cross section area and dimensions for rear and front spar at $(\mathrm{z} / \mathrm{w})=1$. The applied normal stress on both spars along semi-span is shown in Fig.5.

To demonstrate the effect of $(\mathrm{z} / \mathrm{w})$ ratio for each spar, Firstly consider $(\mathrm{z} / \mathrm{w})_{\mathrm{R}}=1$ for rear spar, and $(\mathrm{z} / \mathrm{w})_{\mathrm{F}}$ for front spar is varied from $(0.5-8)$ as shown in Fig.6. at $(\mathrm{z} / \mathrm{W})_{\mathrm{R}}=1$, the optimum value of $(\mathrm{z} / \mathrm{w})_{\mathrm{F}}=0.8, \sigma_{1}=313 \mathrm{Mpa}, \sigma_{2}=204 \mathrm{Mpa}$ and wing weight $20.05 \mathrm{~kg}$., and when consider $(\mathrm{z} / \mathrm{w})_{\mathrm{F}}=1$ for front spar, and $(\mathrm{z} / \mathrm{w})_{\mathrm{R}}$ for rear spar is varied from $(0.2-8)$ as shown in Fig.7. at $(\mathrm{z} / \mathrm{w})_{\mathrm{F}}=1$, the optimum value of $(\mathrm{z} / \mathrm{w})_{\mathrm{R}}=0.4$, $\sigma_{1}=280 \mathrm{Mpa}, \sigma_{2}=324 \mathrm{Mpa}$ and wing weight $19.2 \mathrm{~kg}$.

\section{Searching Method}

The objective function is minimizing the wing weight subjected to structure failure and the design parameters are the height to width flange ratio for both front and rear spars $\left[(z / w)_{F},(z / w)_{R}\right]$. The structure failure is represented as the maximum normal stresses should be less than the material yield strength. The maximum normal stresses are calculated for the two spars along $z$ direction. The mathematical representation of the optimization problem can be written as follows:

Subjected to

$$
\min f(x)=w_{v}
$$

$$
\begin{aligned}
& \left(\sigma_{1}\right)_{\text {max }} \leq\left(\sigma_{\text {yis }}\right)_{\text {material }} \\
& \left(\sigma_{2}\right)_{\text {max }} \leq\left(\sigma_{\text {yield }}\right)_{\text {material }}
\end{aligned}
$$




$$
0.2 \leq X \leq 2, \quad X=\left[(z / w)_{F},(z / w)_{R}\right]
$$

This method is applied by changing the two flanges ratios, obtains a full data for the flanges ratios and their corresponding weight, and stresses as shown in Fig.6, and Fig.7. Then by searching in the accepted values of flanges ratios (satisfy the constraints), the minimum weight is obtained and its corresponding dimensions.

The consumed time to perform this method is about 3 minutes.

\section{Gradient-Based Method}

The objective function is minimizing the wing weight subjected to structure failure and the design parameters are the height to width flange ratio for both front and rear spars $\left[(\mathrm{s} / w)_{p},(\mathrm{~g} / w)_{\mathbb{R}}\right]$. The structure failure is represented, as the maximum normal stresses are less than the material yield strength. The maximum normal stresses are calculated for the two spars along $z$ direction. The mathematical representation of the optimization problem can be written as follows:

$$
\min f(x)=W_{w}
$$

Subjected to

$$
\begin{gathered}
\left(\sigma_{1}\right)_{\text {max }} \leq\left(\sigma_{y i a l d}\right)_{\text {matsial }} \\
\left(\sigma_{2}\right)_{\text {max }} \leq\left(\sigma_{y i a l d}\right)_{\text {matsial }} \\
0.2 \leq X \leq 2, \quad X=\left[(g / w)_{F},(g / w)_{R}\right]
\end{gathered}
$$

This method is applied by integrate the matlab optimization toolbox with the developed codes to obtain the minimum weight with its corresponding dimensions using the gradient-based optimization method. The advantage of this method is that the time consumed in running the program is smaller than the searching and genetic algorithms. The ratios $(z / w)_{p},(z / w)_{R}$ are calculated to allow the rear and front stresses to be the same that leads to decreases the flanges area and the weight as shown in Fig.12 and Fig.13 subjected to the maximum allowable stress as shown in Fig.14 and Fig. 15.

The consumed time to perform this method is about 45 minutes.

\section{Genetic algorithm method}

The objective function is minimizing the wing weight subjected to structure failure and the design parameters are the height to width flange ratio for both front and rear spars $\left[(z / w)_{p},(z / w)_{\mathbb{R}}\right]$. The structure failure is represented, as the maximum normal stresses are less than the material yield strength. The maximum normal stresses are calculated for the two spars along $z$ direction. The mathematical representation of the optimization problem can be written as follows:

Subjected to

$$
\min f(x)=W_{w}
$$




$$
\begin{gathered}
\left(\sigma_{1}\right)_{\max } \leq\left(\sigma_{y i e l d}\right)_{\text {material }} \\
\left(\sigma_{2}\right)_{\max } \leq\left(\sigma_{y i e l d}\right)_{\text {material }} \\
0.2 \leq X \leq 2, \quad X=\left[(z / w)_{R},(z / w)_{R}\right]
\end{gathered}
$$

This method is applied by integrate the matlab optimization toolbox with the developed codes to obtain the minimum weight with its corresponding dimensions using the genetic algorithm optimization method. The disadvantage of this method is that the time consumed in running the program is too large. The ratios $(z / w)_{F}(z / w)_{R}$ are calculated to allow the rear and front stresses to be the same that leads to decreases the flanges area and the weight as shown in Fig.16 and Fig.17 subjected to the maximum allowable stress as shown in Fig.18 and Fig.19.

The results of this method are the same as the results of the gradient-based method. The consumed time to perform this method is about one week.

\section{Comparison of Results}

The comparison of results is shown in Table 3 and Fig.20. The corresponding weight of each method is shown in Fig.21. The graphical method has a good value of the weight but not the optimum where the design parameter was only one. The design parameters are increased in the three other methods. The searching method is very quick, simple, and robust where the consumed time is about 3 min and the optimum value of the weight is very closed to the gradient and genetic. In this study, the gradient-based algorithm has the same optimum values of the genetic algorithm. In addition, it has less consumed time than the genetic algorithm. This is because the design parameters are only two. Therefore, depending on the consumed time and values, the best method is the searching method. However, this method is not good for cases with three or more design parameters. In that case, the genetic algorithm should be used to obtain the global maximum.

\section{CONCLUSION}

Several optimization methods as Graphical method, Searching method, Gradientbased method and Genetic algorithm method were used to improve wing weight and it was clear that the best method in this case was the searching optimization method. The design parameters are only two which leads to a similarity of both gradient based optimization and genetic results. Therefore, using the gradient-based method in cases of low design parameters are more effective due to the lower processing consumed time. the searching method is very quick (3 min.) and the optimum value of the weight is very closed to the gradient and genetic $(18.77 \mathrm{~kg})$. The range of design parameters $(0.2-2)$ is suitable for front spar and rear spar, was determination by graphical method. The genetic algorithm method has the same optimum values of the gradient-based method. In addition, it has more than consumed time to the gradient-based method. 


\section{REFERENCES}

[1] Dieter, G.E., H. A. Kuhn, and a. S. L. Semiatin, "Handbook of workability and process design", ASM international, 2003.

[2] M. Jolgaf and M., "Billet Shape Optimization for Minimum Forging Load", European Journal of Scientific Research, vol. 24(3), 2008.

[3] lyengar and N., "Optimization in structural design", DIRECTIONS, IIT Kanpur, pp. p. 41-47, 2004.

[4] Jolgaf and M., "FE Analysis and Optimization of Plate Forming Process", in 3rd Engineering Conference on Advancement in Mechanical and Manufacturing for Sustainable Environment, 2010. Kuching, Sarawak, Malaysia.

[5] M. S. Alteyeb and M. Jolgaf, "Optimization of Cantilever Beam for Minimum Weight Using Finite Element Analysis (FEA)", First Libyan Conference on Metal Casting and Processing Technologies, 2017.

[6] J. Arora, Introduction to optimum design: Academic Press, 2004.

[7] V. Guillaumin and G. Mankowski, "Localized corrosion of 2024 T351 aluminium alloy in chloride media", Corrosion Science, vol. 41, pp. 421-438, 1998. 
Table 1. Mechanical properties of aluminum 2024-T4 alloy [7] .

\begin{tabular}{|c|c|c|}
\hline Mechanical property & value & unit \\
\hline Ultimate Tensile Strength & 469 & $\mathrm{MPa}$ \\
\hline Tensile Yield Strength & 324 & $\mathrm{MPa}$ \\
\hline Shear Strength & 283 & $\mathrm{MPa}$ \\
\hline Poisson's Ratio & 0.33 & \\
\hline Modulus of Elasticity & 73.1 & $\mathrm{GPa}$ \\
\hline Shear Modulus & 28 & $\mathrm{GPa}$ \\
\hline Density & 2.78 & $\mathrm{~g} / \mathrm{cm} 3$ \\
\hline
\end{tabular}

Table 2. Weight of wing structure.

\begin{tabular}{|c|c|c|}
\hline & {$[\mathrm{Kg}]$} & \% of total weight \\
\hline Front spare weight & 13.536 & 38.85 \\
\hline Rear spare weight & 9.7152 & 27.88 \\
\hline ribs weight & 11.5927 & 33.27 \\
\hline Total weight & 34.8439 & 100 \\
\hline
\end{tabular}

Table 3. Comparison of results.

\begin{tabular}{|c|c|c|c|c|c|}
\hline Method & $\begin{array}{c}\text { Weight } \\
\text { kg }\end{array}$ & $(z / w)_{F}$ & $(z / w)_{R}$ & $\begin{array}{c}\text { Time } \\
\text { consumed }\end{array}$ & $\begin{array}{l}\% \text { of } \\
\text { reduction }\end{array}$ \\
\hline $\begin{array}{c}\text { Without } \\
\text { optimization }\end{array}$ & 34.84 & 5 & 5 & & \\
\hline graphical method & 23.5 & 1 & 1 & $<1 \min$ & $32.54 \%$ \\
\hline $\begin{array}{l}\text { graphical method } \\
\text { front spar }\end{array}$ & 20 & 0.8 & 1 & $<1 \mathrm{~min}$ & $42.59 \%$ \\
\hline $\begin{array}{l}\text { graphical method } \\
\text { rear spar }\end{array}$ & 19.2 & 1 & 0.4 & $<1 \mathrm{~min}$ & $44.89 \%$ \\
\hline searching method & 18.775 & 0.8 & 0.4 & $3 \mathrm{~min}$. & $46.11 \%$ \\
\hline $\begin{array}{l}\text { gradient-based } \\
\text { method }\end{array}$ & 18.612 & 0.747 & 0.399 & $45 \mathrm{~min}$. & $46.57 \%$ \\
\hline $\begin{array}{c}\text { Genetic algorithm } \\
\text { method }\end{array}$ & 18.612 & 0.747 & 0.399 & 1 week & $46.57 \%$ \\
\hline
\end{tabular}




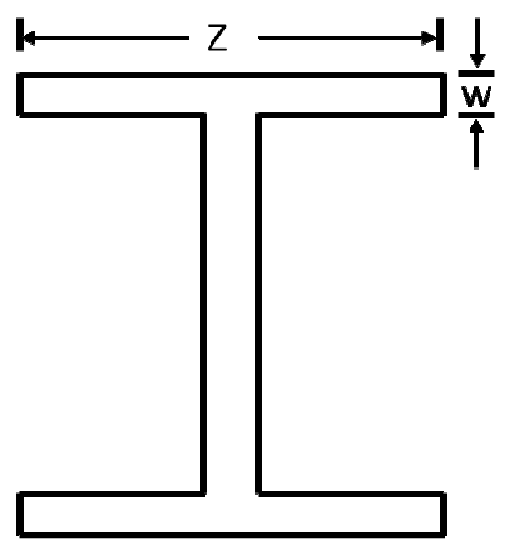

Fig. 1. Spar cross section.

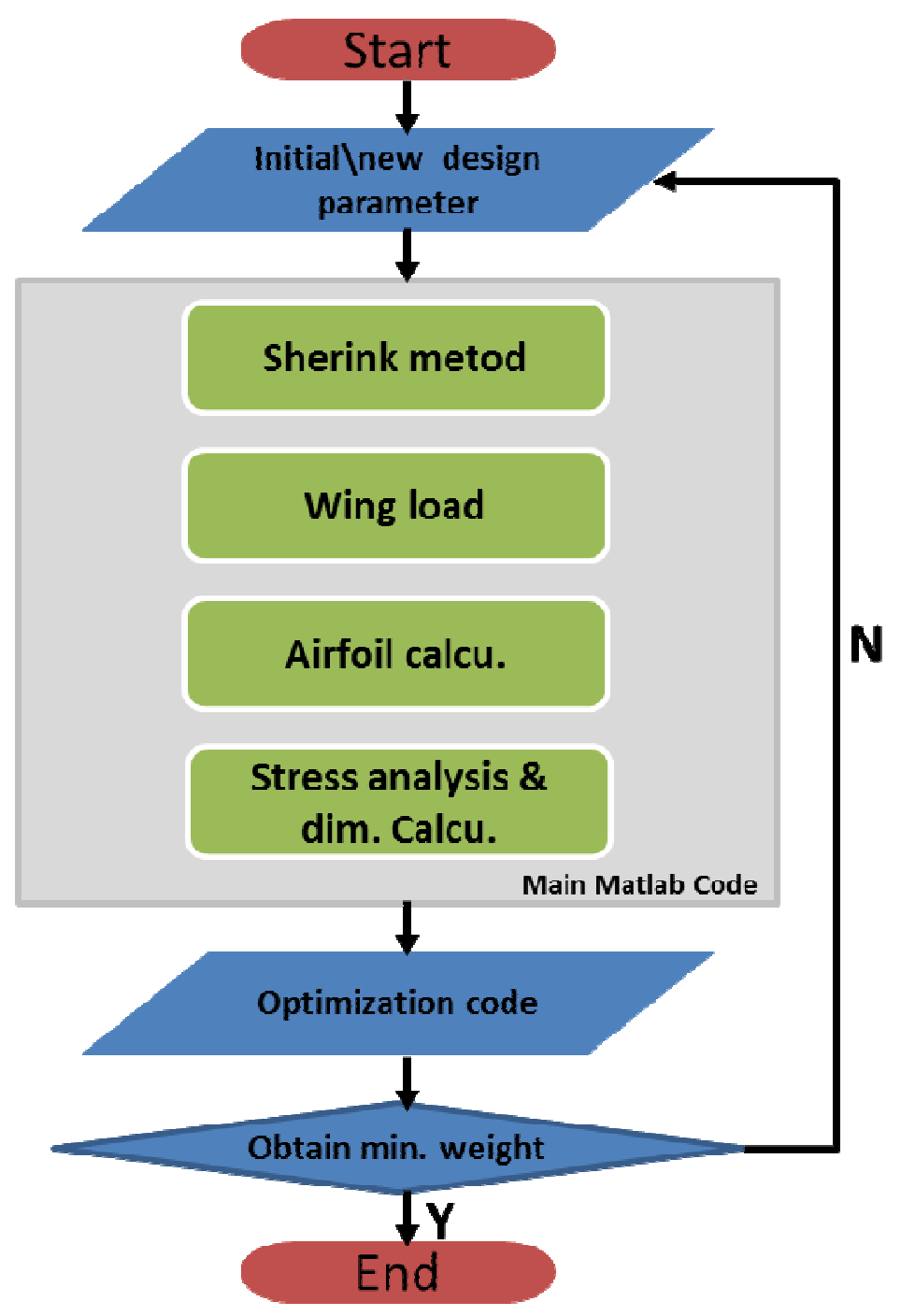

Fig. 2. Matlab codes flow chart. 


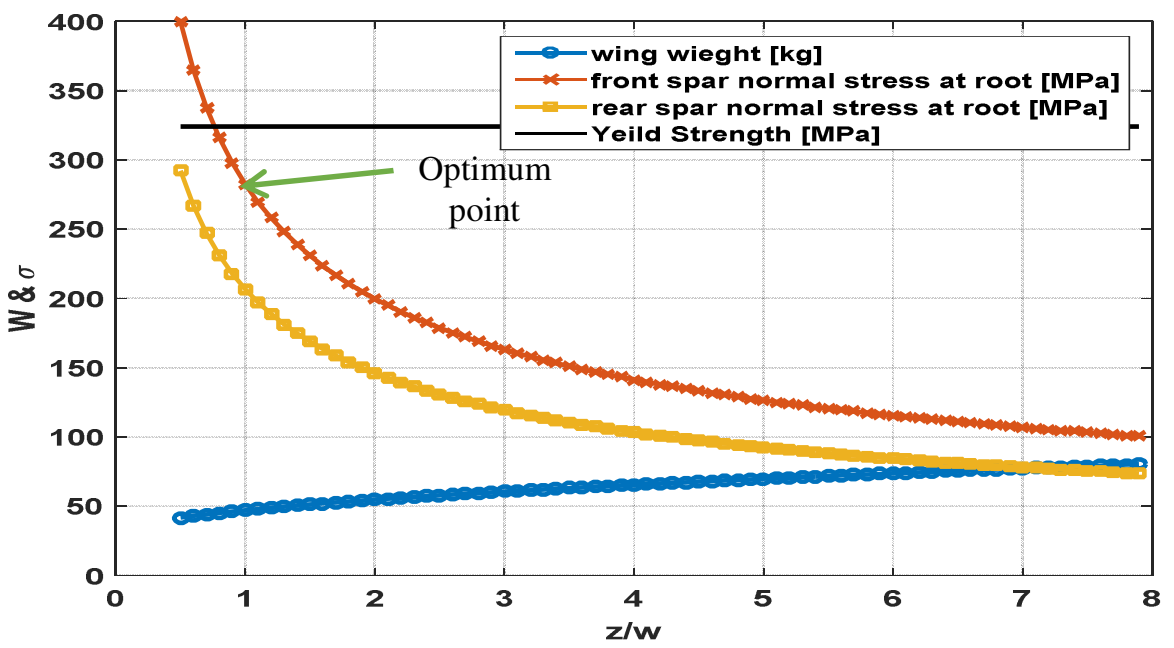

Fig. 3. Graphical representation.
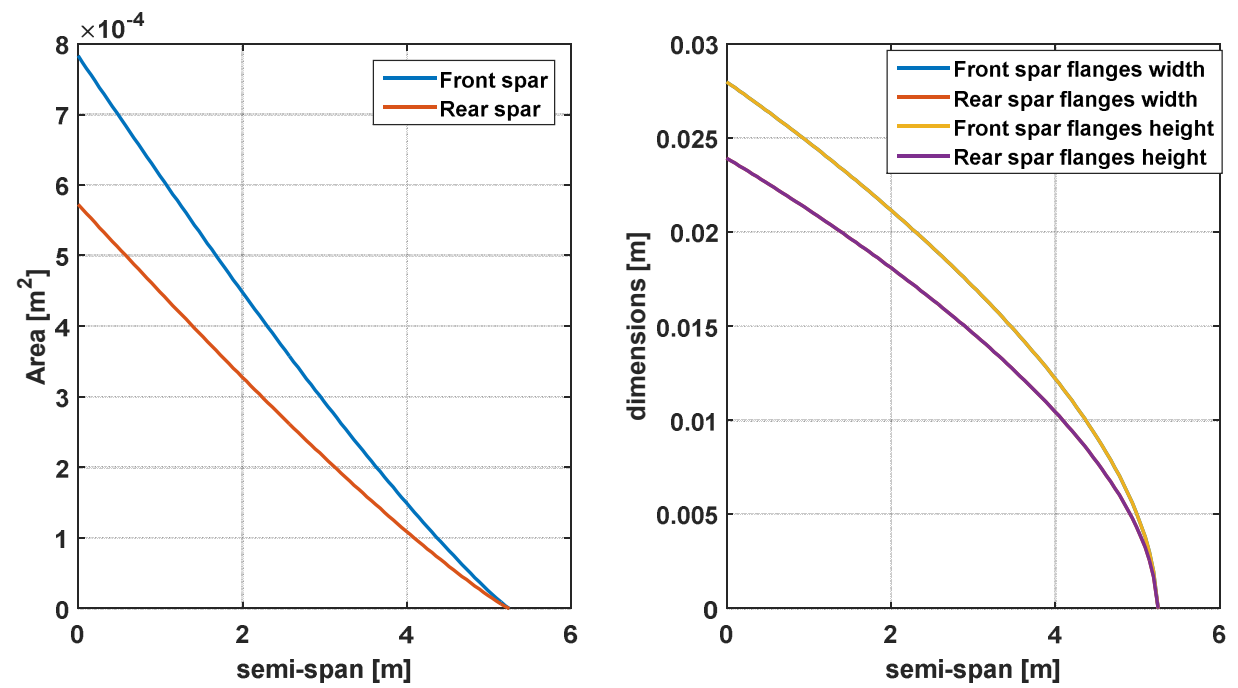

Fig. 4. dimensions of flanges for front and rear spar by graphical method.

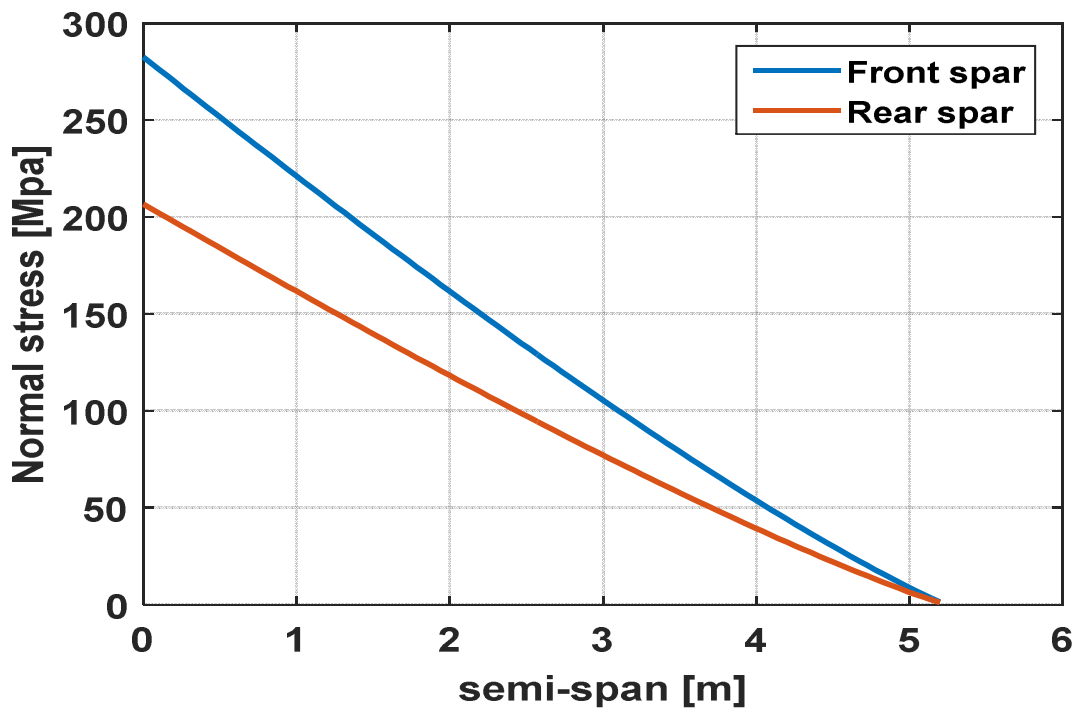

Fig. 5. normal stress on spars by graphical method.. 


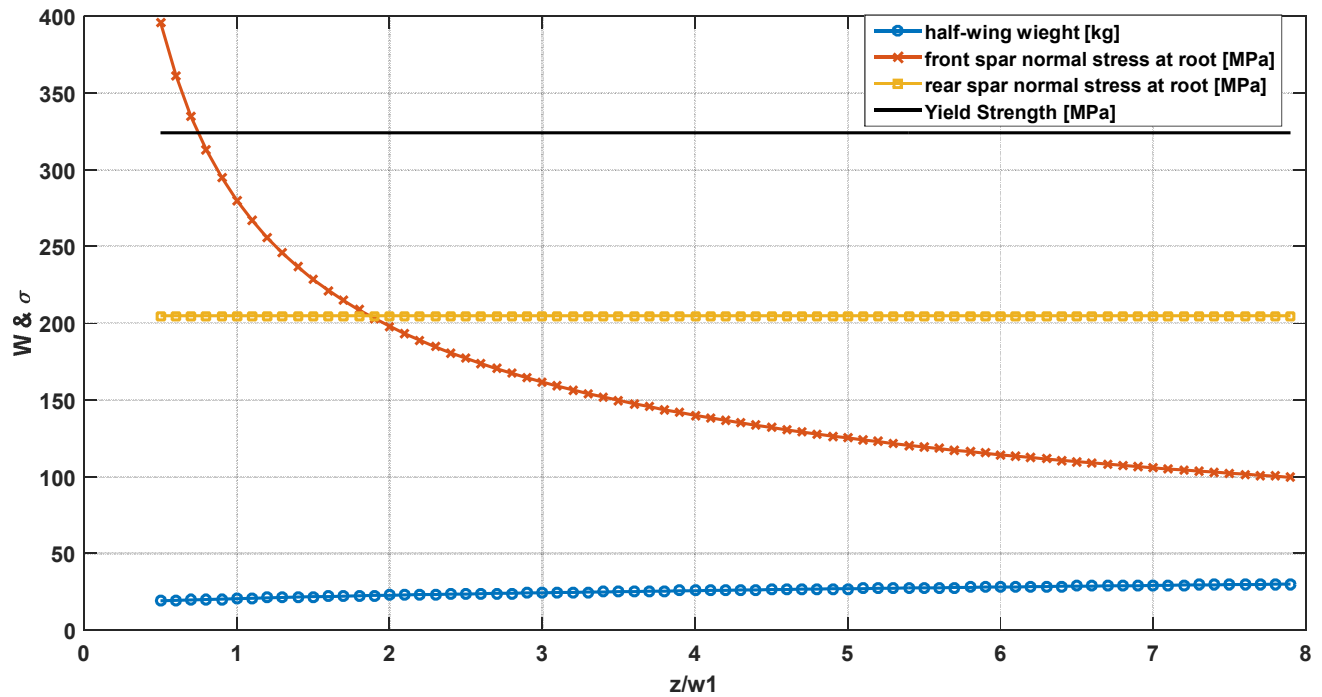

Fig. 6. graphical representation for the front spar ratio.

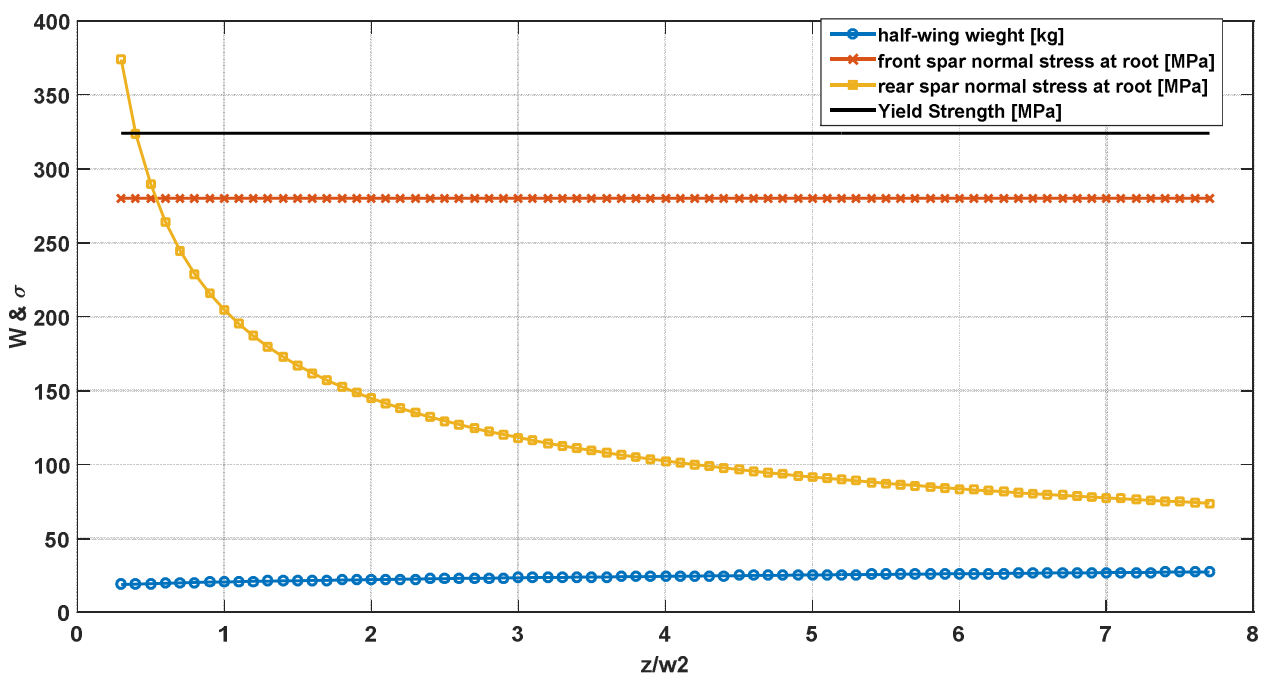

Fig. 7. graphical representation for the rear spar ratio.
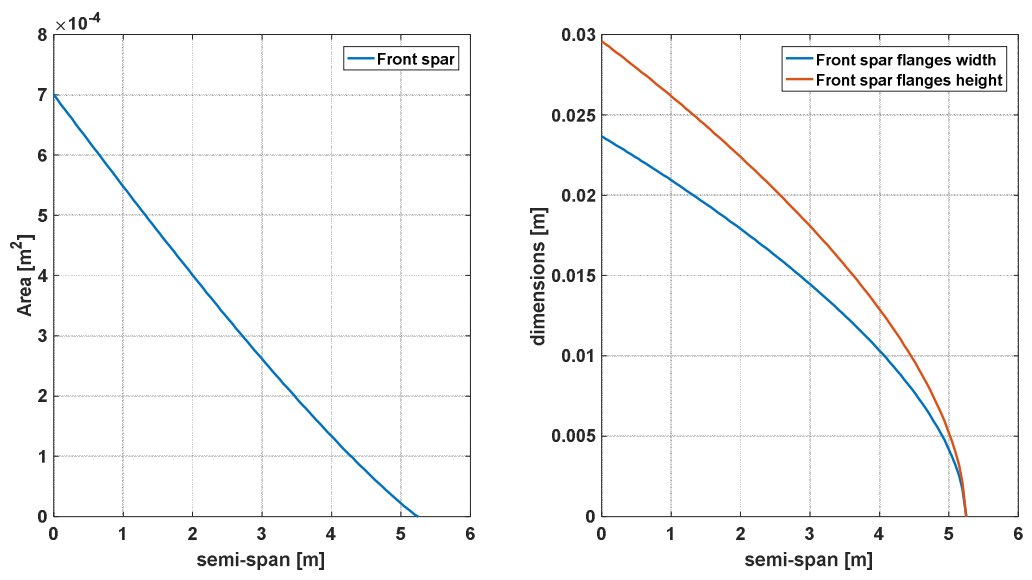

Fig. 8. dimensions of flanges for front spar by searching method. 

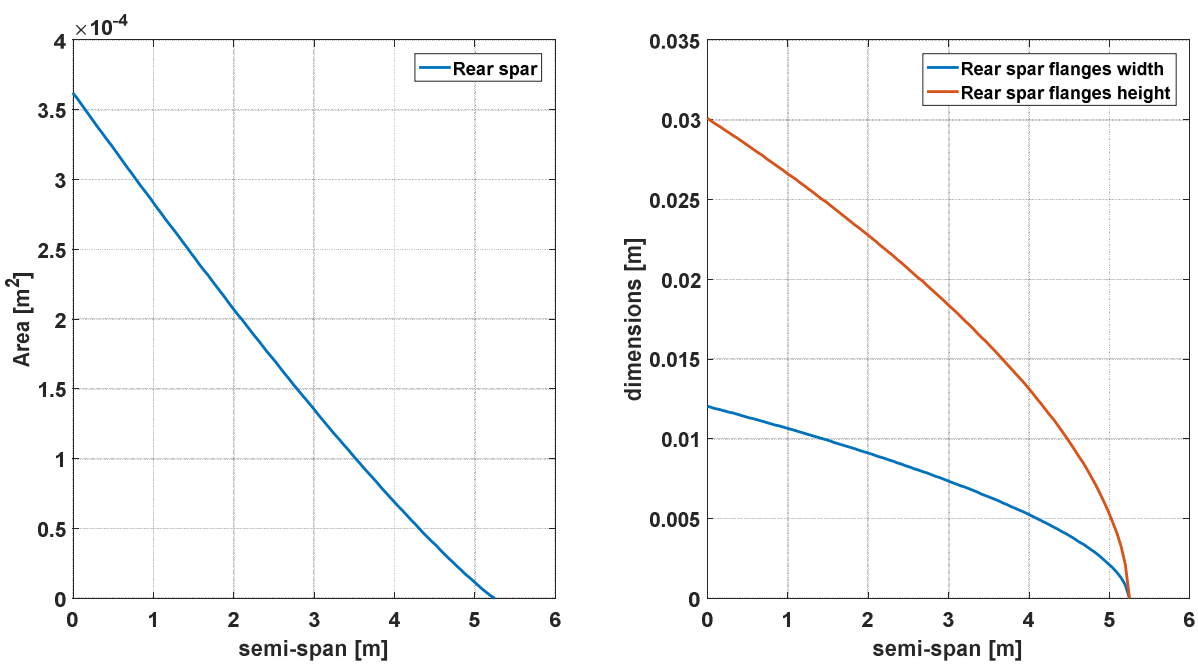

Fig. 9. dimensions of flanges for rear spar by searching method.

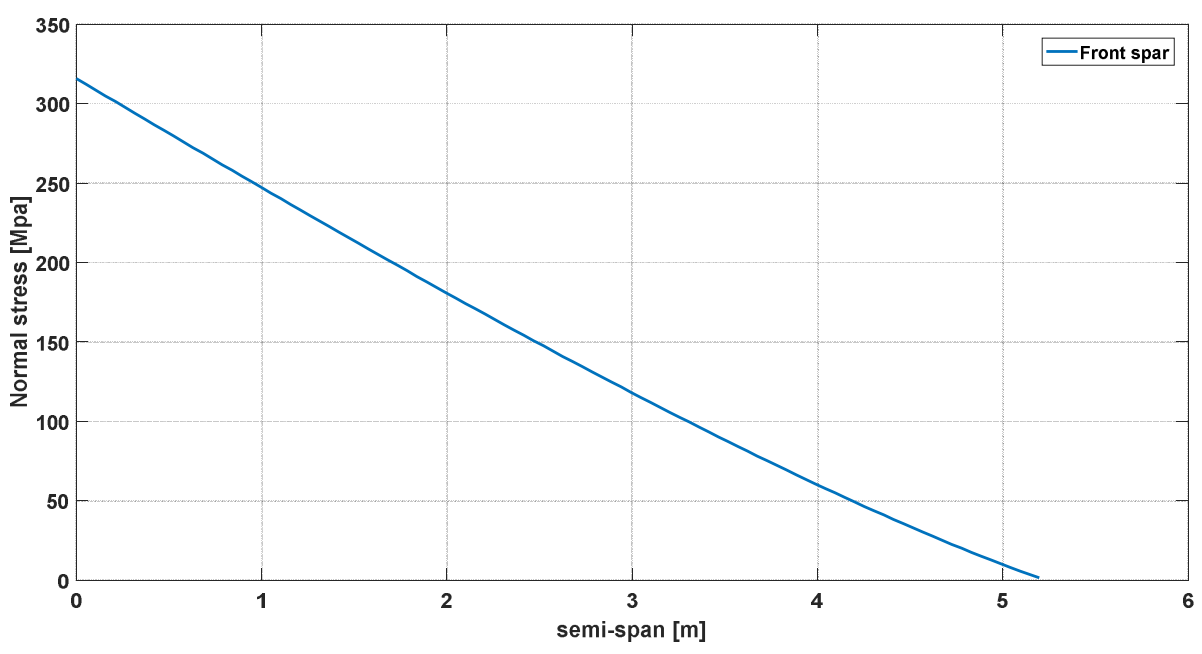

Fig. 10. normal stress on front spar by searching method.

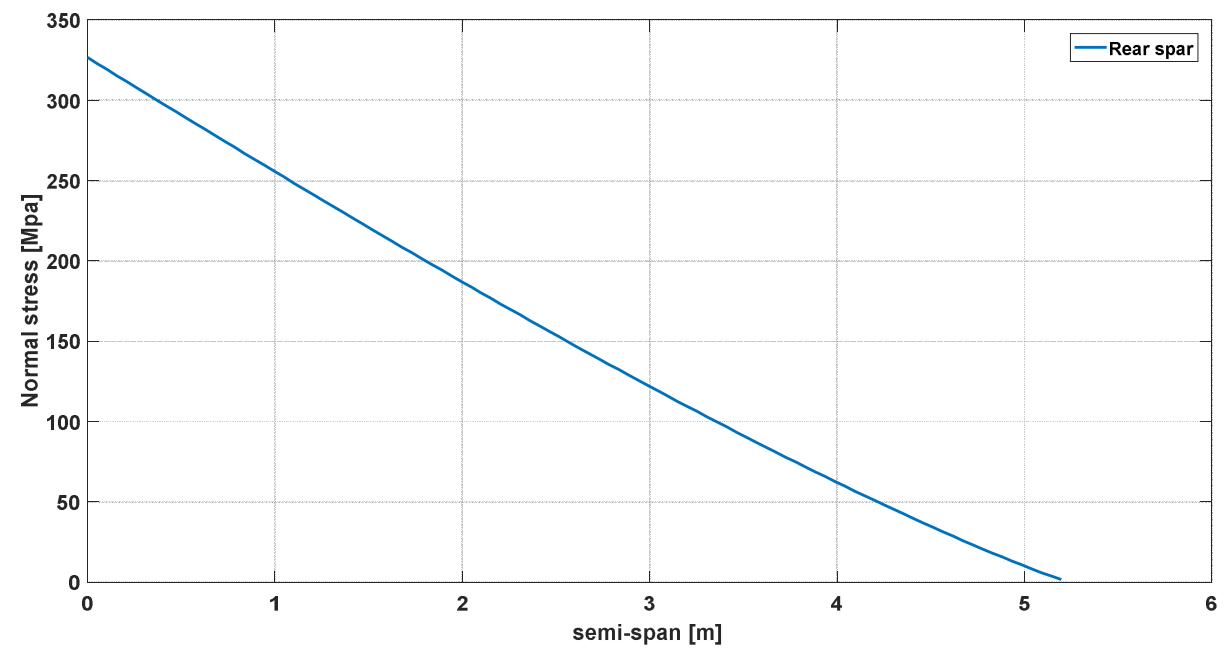

Fig. 11. normal stress on rear spar by searching method. 

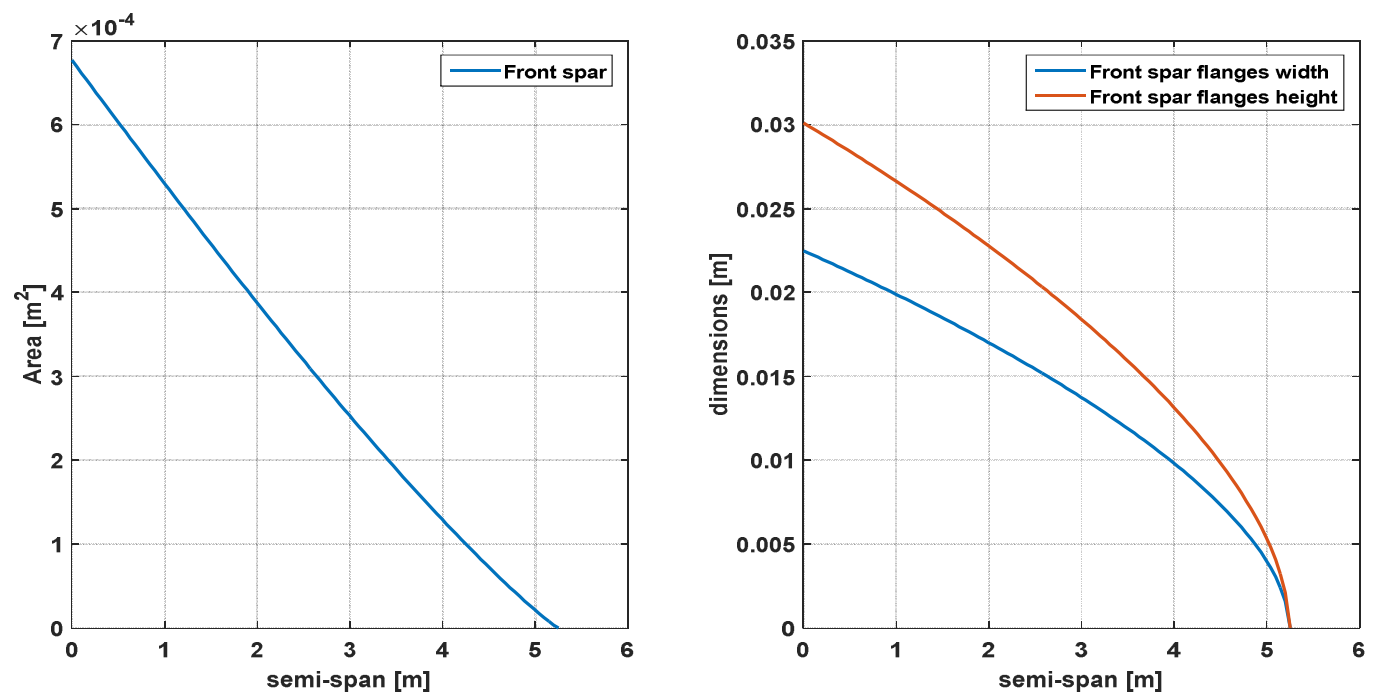

Fig. 12. dimensions of flanges for front spar by gradient-based method.
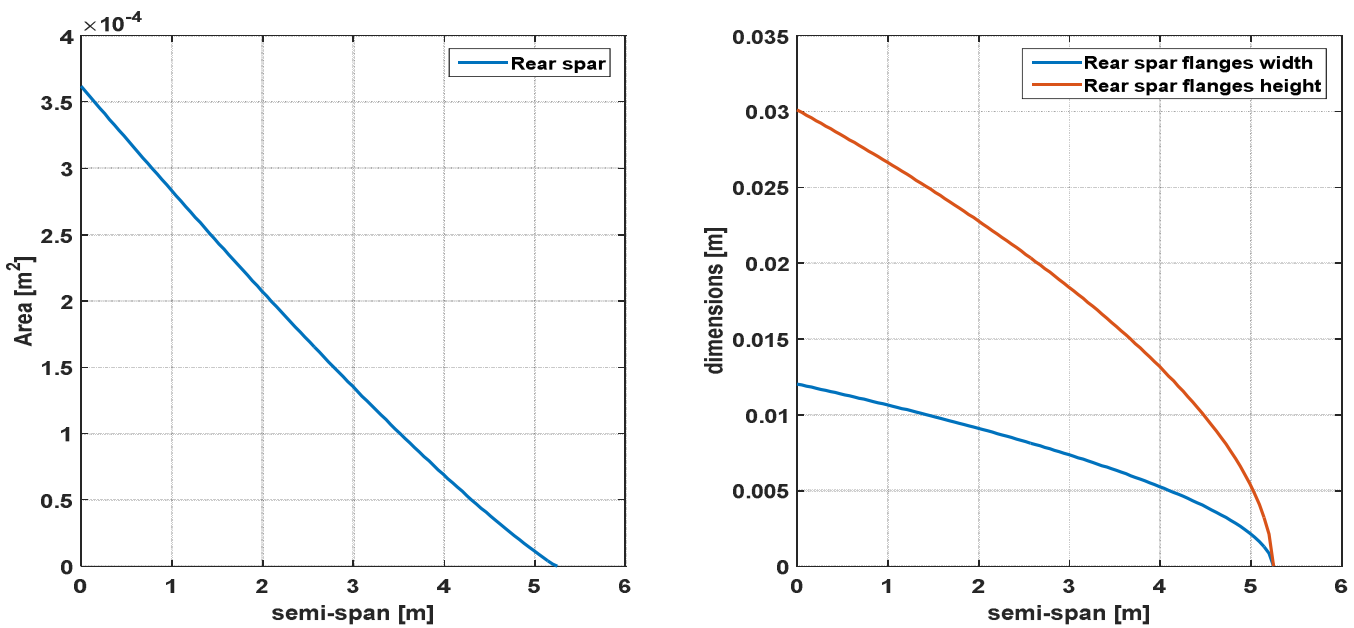

Fig. 13. dimensions of flanges for rear spar by gradient-based method.

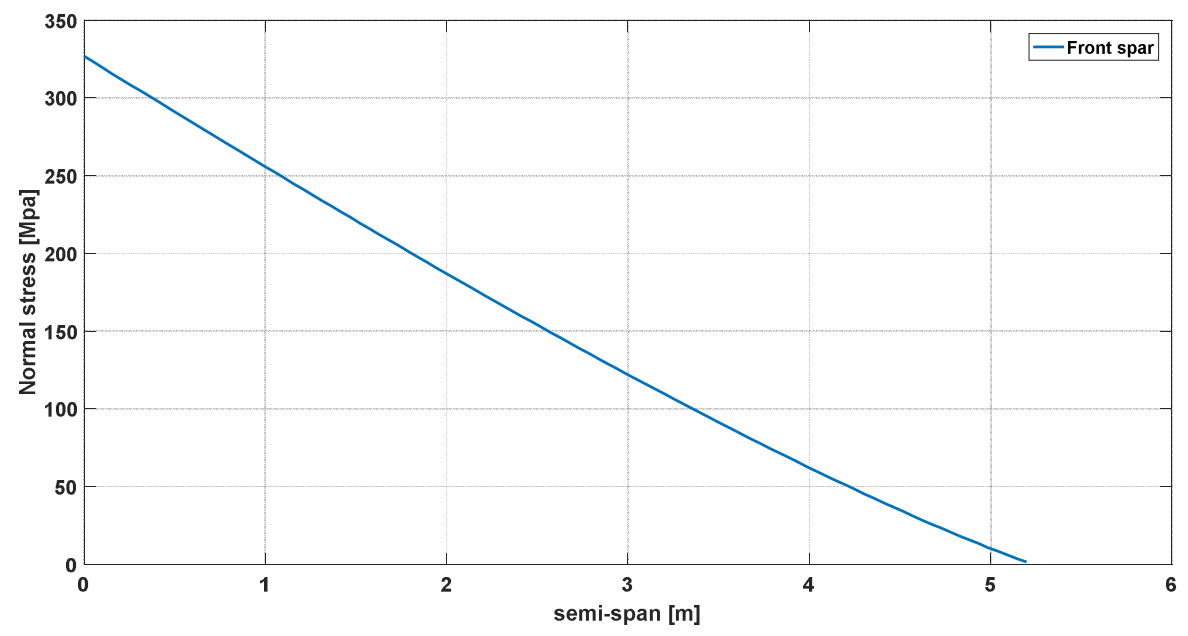

Fig. 14. normal stress on front spar by gradient-based method. 


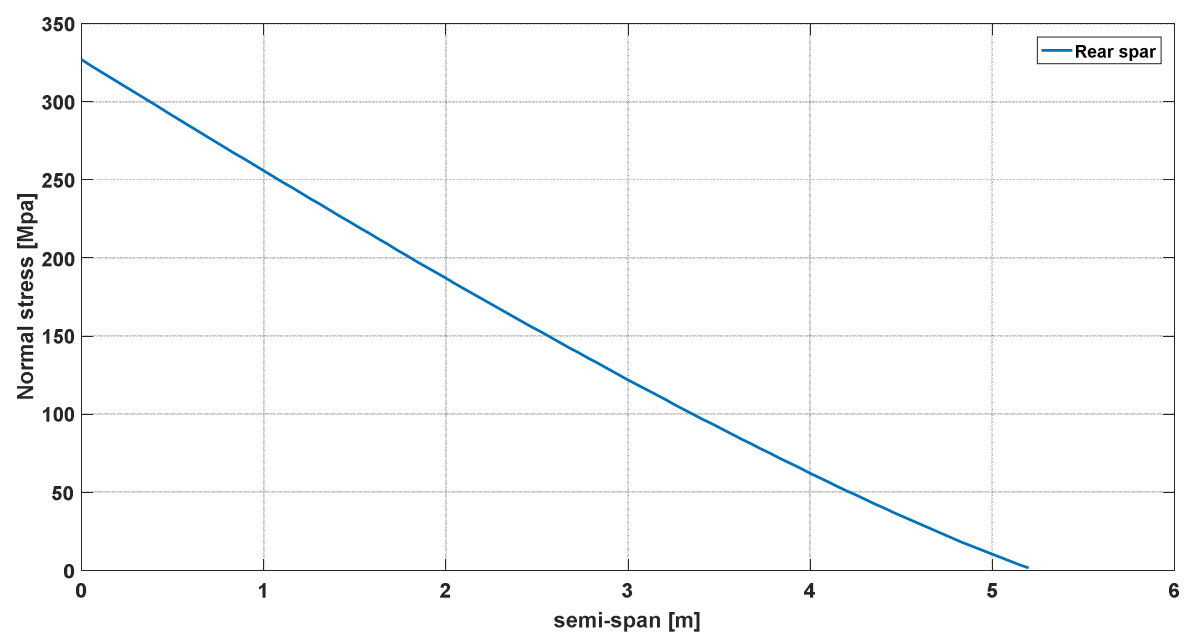

Fig. 15. normal stress on rear spar by gradient-based method.
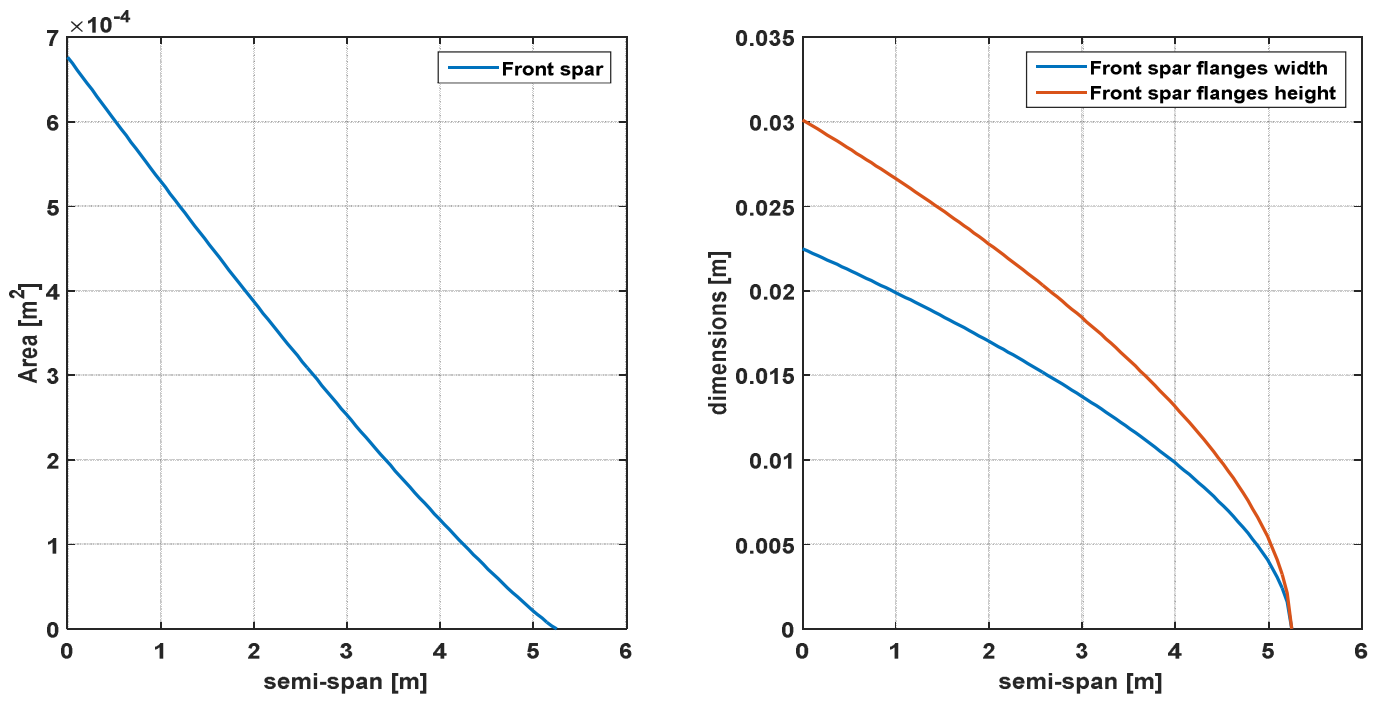

Fig. 16. dimensions of flanges for front spar by genetic algorithm method.
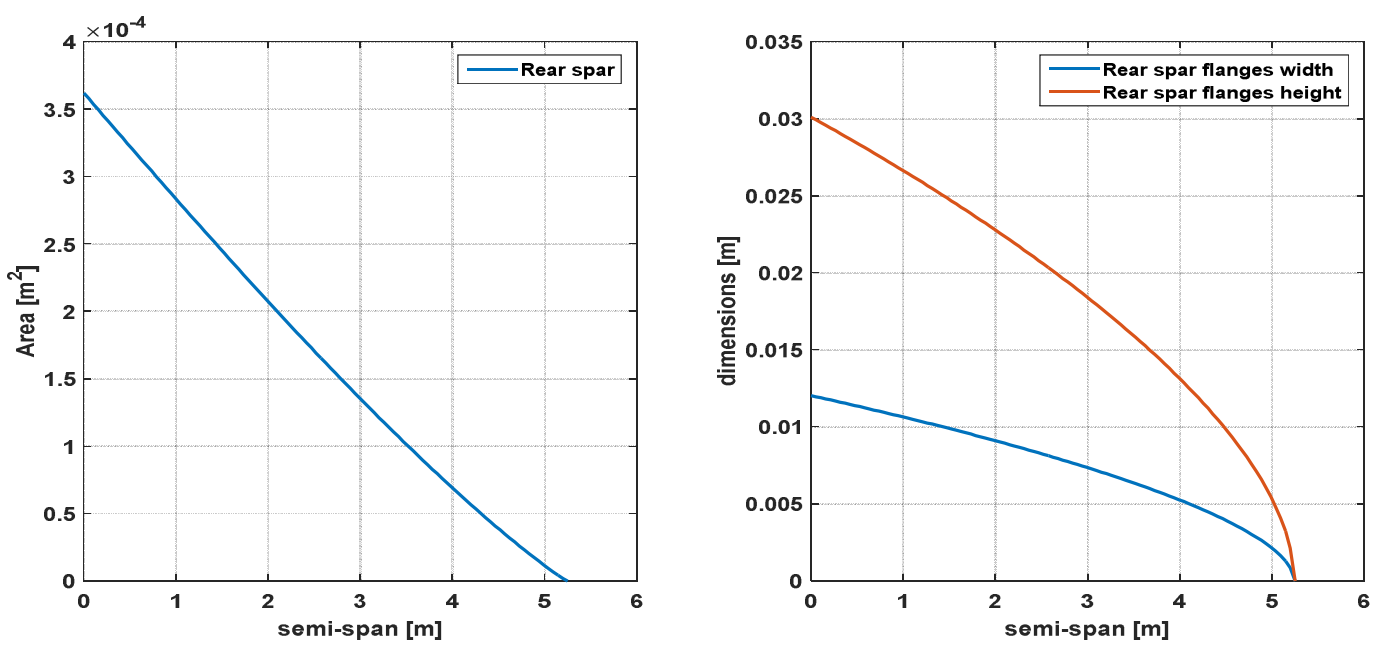

Fig. 17. dimensions of flanges for rear spar by genetic algorithm method. 


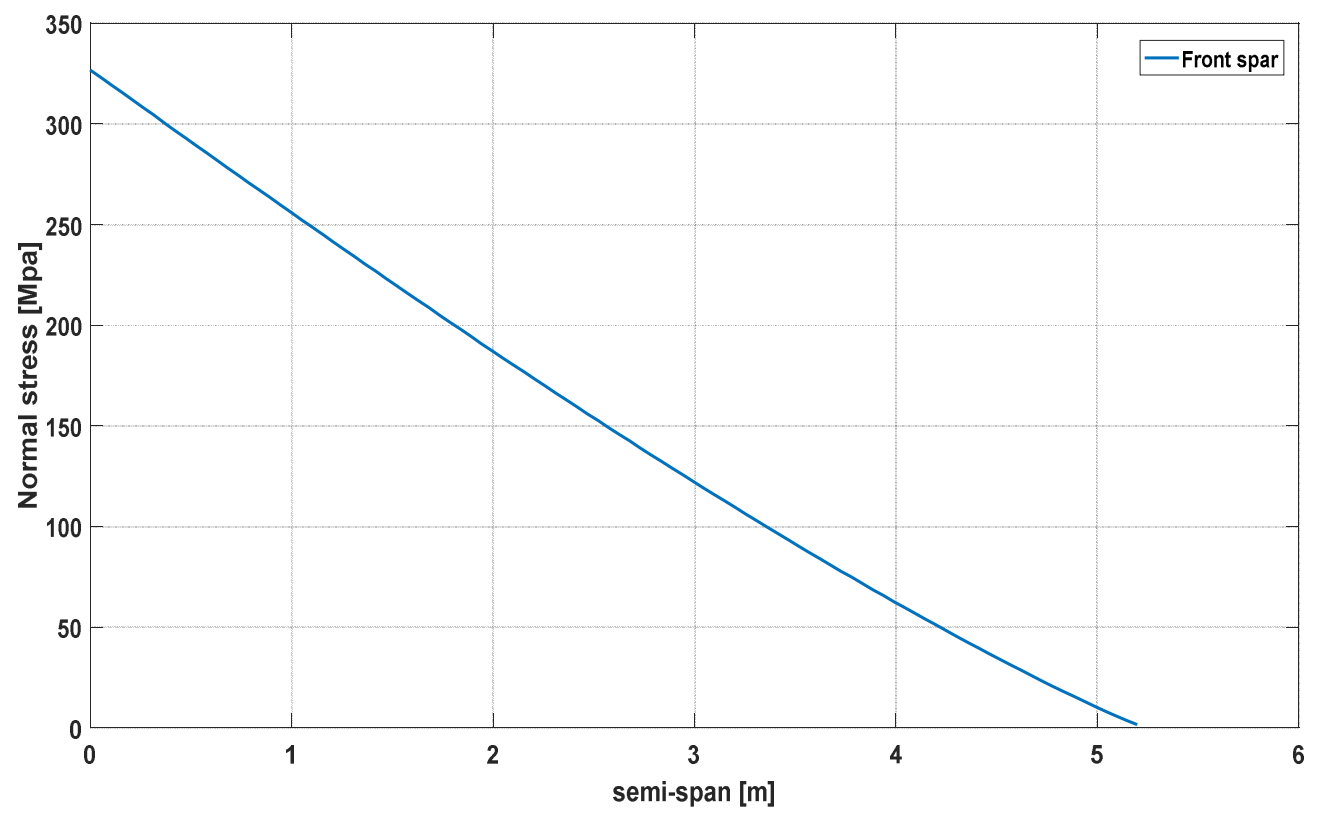

Fig. 18. normal stress on front spar by genetic algorithm method.

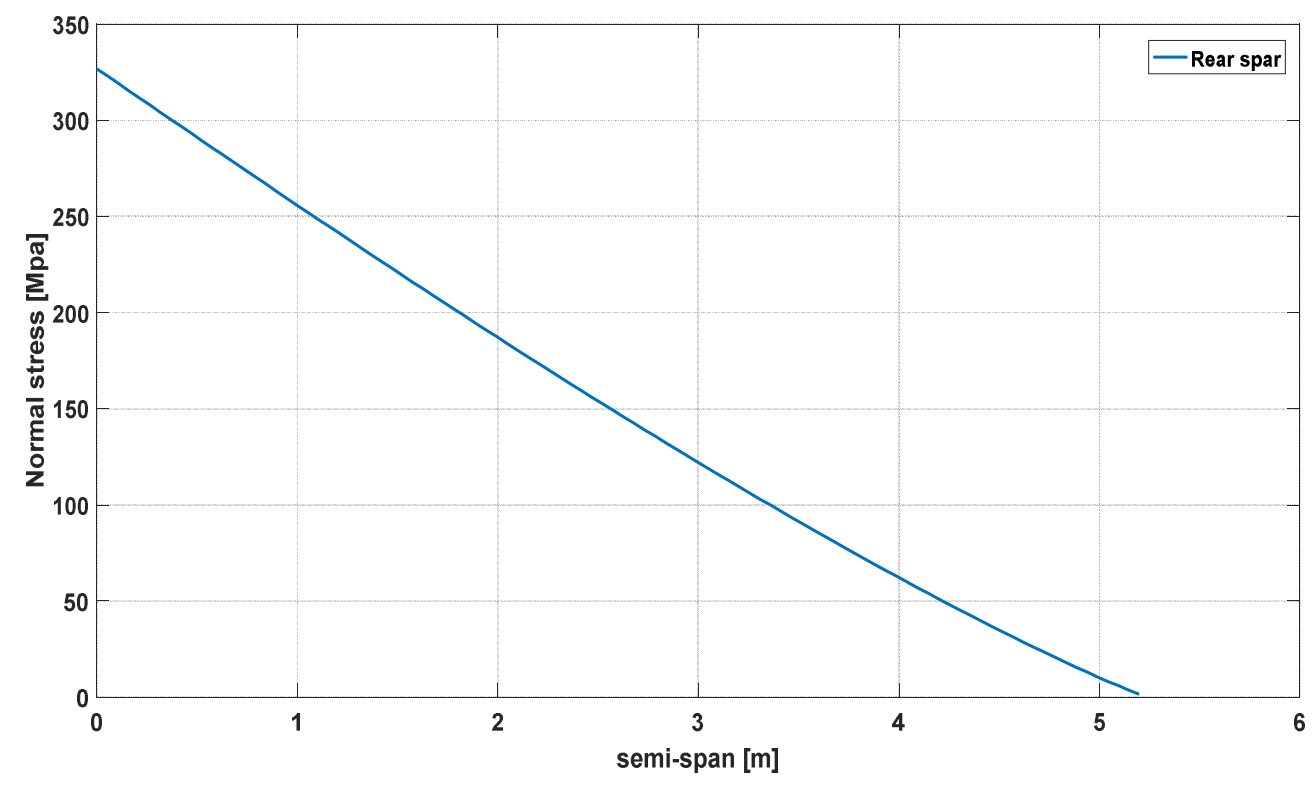

Fig. 19. normal stress on rear spar by genetic algorithm method. 


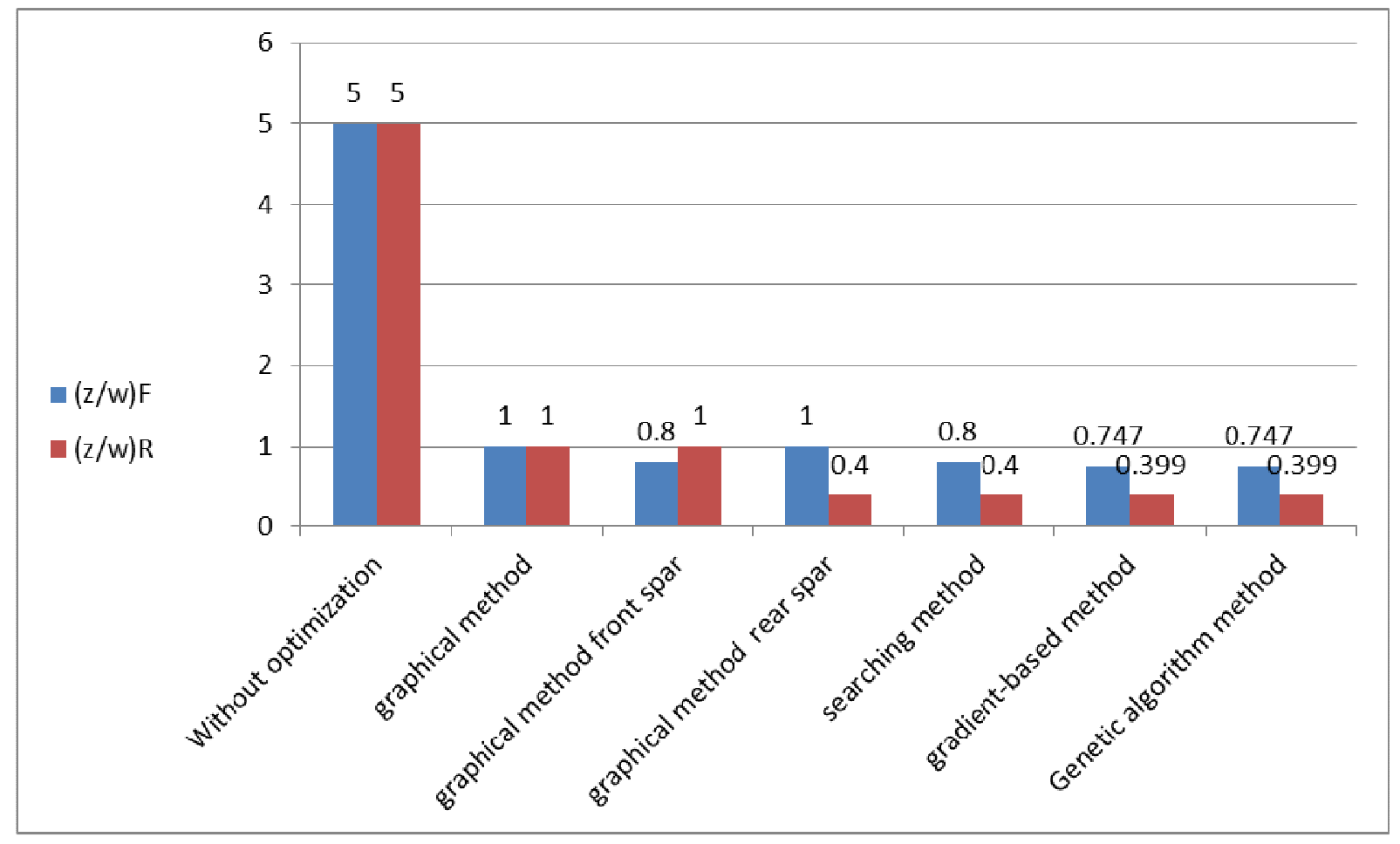

Fig. 20. Comparison of reduction ratio.

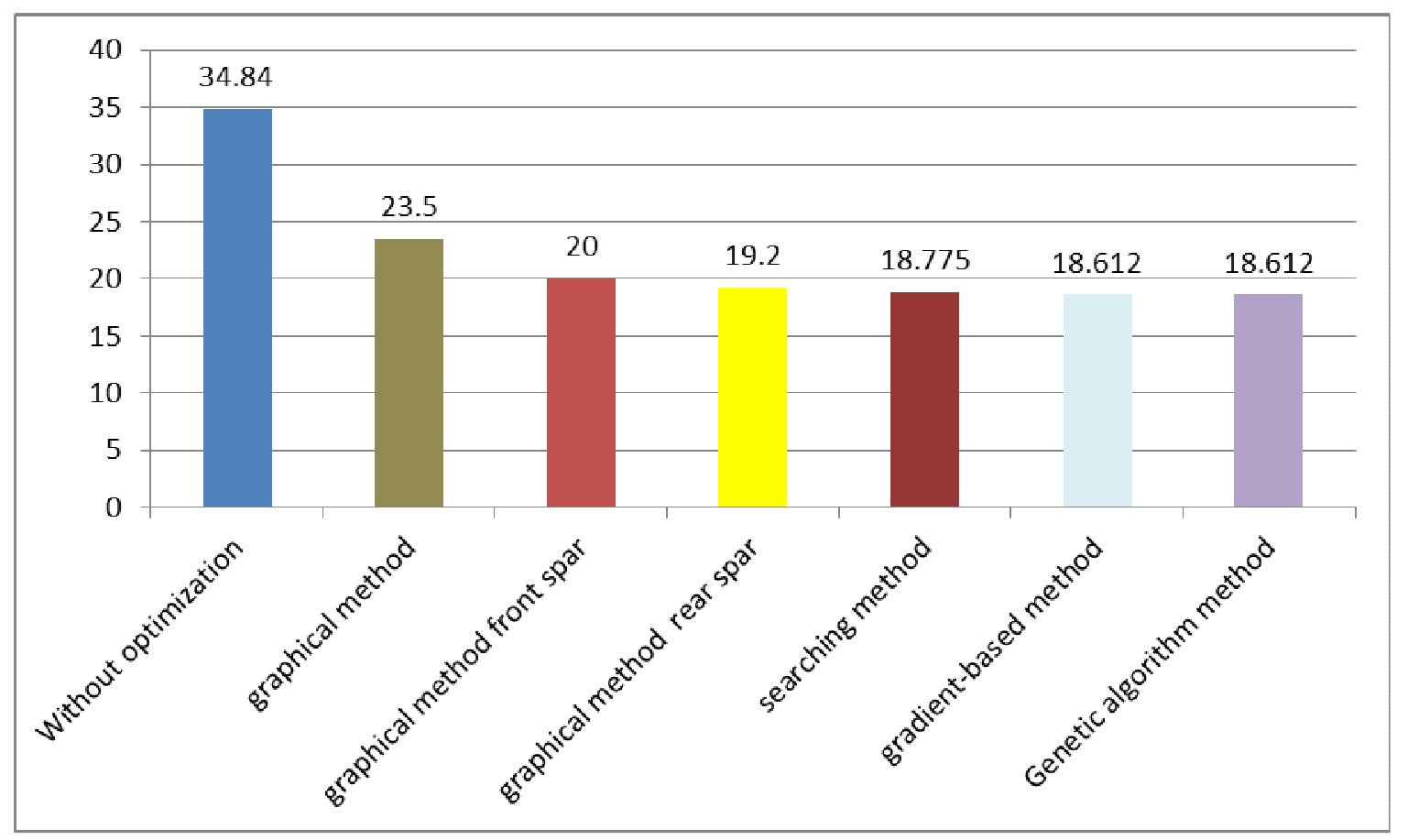

Fig. 21. Weight for each case. 